\title{
Anomalous Left Coronary Artery from the Pulmonary Artery: Mini-Review
}

\author{
${ }^{1}$ Michael Gebreyohannes Tedla, M.D, ${ }^{2}$ Dawit Kibru Worku, M.D \\ ${ }^{1}$ Department of Internal Medicine, Mountain View Hospital, Las Vegas, Nevada, USA \\ ${ }^{2}$ Department of Internal Medicine, Bahir Dar University, Addis Ababa, Ethiopia
}

\begin{abstract}
Anomalous left coronary artery from the pulmonary artery (ALCAPA) is an infrequent congenital cardiac disease with an incidence of 1 in 300,000 live births. ALCAPA is among the frequent cause of myocardial ischemia and infarction in children with a mortality rate of $90 \%$ if early intervention is not initiated. A comprehensive nomenclature system enlisting all types of ALCAPA is depicted in the Congenital Heart Surgery Nomenclature and Database Project. Most experts agree that clinicians should bare high index of suspicion while managing infants and children with global myocardial dysfunction. Surgical management is the gold standard of treatment for ALCAPA. It has undergone substantial advancement since its commencement. To avoid detrimental outcomes, it's prudent to exercise high index of suspicion, order apposite investigations, and manage and refer patients to appropriate centers. In Conclusion: ALCAPA can be operated on with good outcomes. Persistent Mitral regurgitation and a moderate rate of late valve repair demands close follow-up.
\end{abstract}

Keywords: Anomalous left coronary artery, Coronary Artery, Heart surgery, Pulmonary artery, Congenital anomaly

\section{INTRODUCTION}

Anomalous left coronary artery from the pulmonary artery (ALCAPA) is an infrequent congenital cardiac disease with an incidence of 1 in 300,000 live births. ALCAPA was first reported by Alexei Ivanovich Abrikosov in 1911, on his postmortem report entitled "a left ventricular aneurysm with anomalous origin of the left coronary artery from pulmonary artery in a 5-month old child." A detailed and complete clinical account was given in 1933 by three physicians Edward Bland, Paul Dudley White, and Joseph Garland. Hence, today we call a typical case of ALCAPA as Bland-WhiteGarland syndrome. In their original report, pathological review of nine cases of ALCAPA was presented. [1].

ALCAPA is among the frequent causes of myocardial ischemia and infarction in children with a mortality rate of $90 \%$ if early intervention is not initiated. Early surgical intervention on diagnosis to restore a two-coronary system circulation is the endeavor of current treatment. There are many reports of ongoing and recurrent myocardial damage and silent ischemia despite early initiation of surgical intervention. In addition to that there is high risk of sudden cardiac death and arrhythmia. Hence, experts recommend regular postsurgical follow-ups [2].

Patients presenting with ALCAPA during adult ages is extremely rare. Most adult cases report nonspecific symptoms including fatigue, syncope, arrhythmia, or less often chest pain. Physical examination may reveal a cardiac murmur and signs of congestive heart failure. The murmurs can be systolic or continuous types. The systolic murmur can arise secondary to ischemic mitral regurgitation and the continuous murmur can be caused by the flow of huge volume of blood via the collateral vessels [3].

\section{Classification}

A comprehensive nomenclature system enlisting all types of ALCAPA origin is depicted in the Congenital Heart Surgery Nomenclature and Database Project [4].

Even though there are lists of possible places where the left coronary artery (LCA) originate in ALCAPA, the commonest is from the posterior facing sinus of the Pulmonary artery (PA). The other 
rare possibilities include from any part of the main PA or its branches. It may also have an intramural course like when the LCA comes from the junction of the main PA and right PA or the right PA. This is a highly exceptional association. And, the literature is limited to a few case reports and small series [1].

\section{Diagnosis}

Most experts agree that clinicians should bare high index of suspicion while managing infants and children with global myocardial dysfunction. The condition's symptoms and signs can mimic a list of diseases and present a challenge for physicians caring these patients. The exceeding rarity of the anomaly adds even more challenge to suspect and order diagnostic investigations. Patients usually present by 8 weeks of age with signs and symptoms of myocardial infarction and heart failure. The most imperative differential diagnosis is dilated cardiomyopathy, and others include congestive heart failure, massive cardiomegaly, ischemic signs on the electrocardiogram (ECG), and a murmur of mitral regurgitation. It is mostly diagnose with noninvasive methods, although some cases need more invasive modalities such as coronary angiography. Studies show it's not uncommon an undiagnosed or misdiagnosed ALCAPA leading to mitral valve replacement or death. To avoid these detrimental outcomes, it's prudent to exercise high index of suspicion, order apposite investigations, and manage and refer patients to appropriate centers $[2,5,6]$.

\section{Treatment}

Surgical management is the gold standard treatment for ALCAPA. It has undergone substantial advancement since its commencement. It was first attempted by Willis J. Potts from Children's Memorial Hospital in Chicago. He successfully created an aortopulmonary anastomosis in two patients. The idea behind his method was to create anastomosis and increase PA blood flow and as a result, increase left coronary artery oxygen saturation [7].

Aortic implantation is the treatment of choice for anomalous origin of the left coronary artery (Figure). Methods such as direct transfer, tubular reconstruction, and in situ transfer make such implantation possible in all patients regardless of the site of coronary origin, distance from the aorta, or coronary artery configuration [8].

Isomatsu et al demonstrated that impaired left ventricular function controlled in the long term after 2coronary repair. They recommend that the simultaneous mitral annuloplasty should be performed at the time of operation for patients who have mitral incompetence with anomalous origin of the left coronary artery [9].

Even though exceedingly rare, anomalous left coronary artery from the right PA with aortic fusion is intricate to diagnose. It's also difficult to repair when there is minimal intramural course [10].

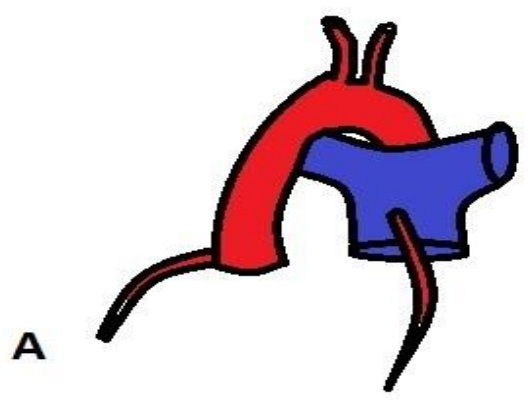

$\mathbf{B}$

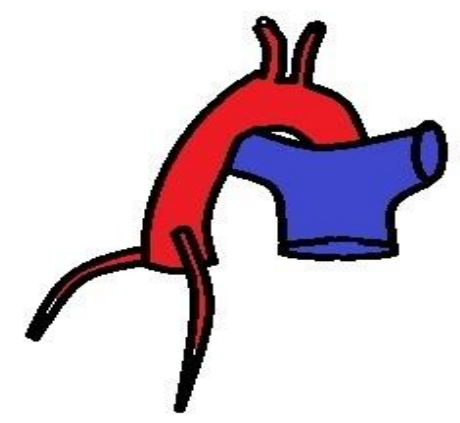

Figure A. Anomalous left coronary artery from the pulmonary artery,

Figure B. After surgical implantation of anomalous left coronary artery to the aorta.

\section{Prognosis}

Early diagnosis and improvements in surgical techniques dramatically improve prognosis. Literatures point untreated cases may have mortality rate as high as $90 \%$ only in the first year of life. Death can 
occur due to myocardial ischemia or infarction and mitral valve regurgitation and its complications resulting in congestive heart failure (CHF). In some cases, because of extensive collateral circulation, patients survive until adulthood. These adult ALCAPA patients are at risk of ischemic heart disease, arrhythmia and sudden death. Early diagnosis of the anomaly is therefore very imperative to improve the prognosis $[3,11]$.

Complications after surgical correction are rare. The need for future valve surgery depends on the occurrence of hemodynamic complications such as permanent mitral valve damage following surgery. Mitral annuloplasty may decrease the risk of such complications [12].

Late complications related to coronary artery insufficiency are more likely to occur if revascularization was accomplished by surgical ligation, occluded or stenotic bypass graft, or intrapulmonary tunnel technique. Inadequate growth of the coronary anastomosis is possible, although unlikely, if surgical reimplantation of the left coronary artery was performed [12, 13].

In conclusion, ALCAPA can be managed on with good outcomes. Persistent mitral regurgitation with its complication and a moderate rate of late valve repair demands close follow-up [14].

\section{REFERENCES}

[1] Phillip S. Naimo, Edward Buratto, Igor E. Konstantinov., A curious course of an intramural anomalous left coronary artery from the pulmonary artery, J Thorac Cardiovasc Surg 2016; 1-2.

[2] Ali Dodge-Khatami, Constantine Mavroudis, Carl L. Backer., Anomalous Origin of the Left Coronary Artery from the Pulmonary Artery: Collective Review of Surgical Therapy, Ann Thorac Surg 2002; 74: 946-55.

[3] RV. Pruijsten, A.J.J.C. Bogers, A.M.W. Alings., Anomalous origin of the left coronary artery connected to the pulmonary artery in a 31-year-old woman, Net/ Heart J 2005; 13:423-5.

[4] Gaynor JW1, Jacobs JP, Jacobs ML, Elliott MJ, Lacour-Gayet F, Tchervenkov CI, Maruszewski B, Mavroudis C; International Congenital Heart Surgery Nomenclature and Database Project., Congenital Heart Surgery Committees of the Society of Thoracic Surgeons. European Association for Cardio-Thoracic Surgery. Congenital Heart Surgery Nomenclature and Database Project: update and proposed data harvest, Ann Thorac Surg. 2002 Mar; 73 (3): 1016-8.

[5] Cochrane AD, Coleman DM, Davis AM, Brizard CP, Wolfe R, Karl TR., Excellent long-term functional outcome after an operation for anomalous left coronary artery from the pulmonary artery, J Thorac Cardiovasc Surg 1999; 117:332-42.

[6] Ohkado A, Yashima M, Ishiyama M, Morishima S, Tei E., Delayed diagnosis of anomalous origin of the left coronary artery 16 years after mitral valve replacement, Ann Thorac Surg 1998; 66:1819-20.

[7] Potts WJ, cited by Kittle CF, Diehl Am, Heilbrunn A., Anomalous left coronary artery arising from the pulmonary artery, J Pediatr 1955;47:196-203.

[8] Kevin Turley, Robert J. Szarnicki, Keith D. Flachsbart, Richard C. Richter, Robert W. Popper, Harold Tarnoff., Aortic Implantation Is Possible in All Cases of Anomalous Origin of the Left Coronary Artery From the Pulmonary Artery, Ann Thorac Surg 1995; 60: 84-9.

[9] Yukihisa Isomatsu, Yasuharu Imai, Toshiharu Shin'oka, Mitsuru Aoki, Yusuke Iwata., Surgical Intervention for Anomalous Origin of the Left Coronary Artery from the Pulmonary Artery: The Tokyo Experience, J Thorac Cardiovasc Surg 2001; 121: 792-7.

[10] T. K. Susheel Kumar, Pranava Sinha, Mary T. Donofrio, Richard A. Jonas., Anomalous left coronary artery fromthe right pulmonary artery with aortic fusion, J Thorac Cardiovasc Surg 2012; 143: 505-7.

[11] M. C. de Kleijn, S.H.H.Kuijpers, F.J.Meijboom., Anomalous left coronary artery arising from the pulmonary artery in an adult woman, Neth Heart J (2016) 24:691-692.

[12] Meyer BW, Stefanik G, Stiles QR, Lindesmith GG, Jones JC., A method of definitive surgical treatment of anomalous origin of left coronary artery. A case report, J Thorac Cardiovasc Surg. 1968 Jul. 56(1):104-7. 
[13] Takeuchi S, Imamura H, Katsumoto K, Hayashi I, Katohgi T, Yozu R, Ohkura M, Inoue T., New surgical method for repair of anomalous left coronary artery from pulmonary artery, J Thorac Cardiovasc Surg. 1979 Jul. 78(1):7-11.

[14] Phillip S. Naimo, Tyson A. Fricke, Yves d'Udekem, Andrew D. Cochrane, MBBS, Andrew Bullock, Terry Robertson, Christian P. Brizard, Igor E. Konstantinov., Surgical Intervention for Anomalous Origin of Left Coronary Artery from the Pulmonary Artery in Children: A LongTerm Follow-Up, Ann Thorac Surg 2016; 101:1842-9.

Citation: Michael Gebreyohannes Tedla \& Dawit Kibru. Anomalous Left Coronary Artery from the Pulmonary Artery: Mini-Review. ARC Journal of Cardiology. 2017; 3(1):13-16.

Copyright: (๑) 2017 Michael Gebreyohannes Tedla \& Dawit Kibru. This is an open-access article distributed under the terms of the Creative Commons Attribution License, which permits unrestricted use, distribution, and reproduction in any medium, provided the original author and source are credited. 